\title{
O RESPEITO À LIBERDADE DE AMAR OU A RUPTURA DO MODELO MONOGÂMICO DE FAMÍLIA?
}

\section{POLYAMORY: RESPECT FOR THE FREEDOM TO LOVE OR BREAK THE MONOGAMOUS FAMILY MODEL?}

${ }^{1}$ Helanne Barreto Varela Gonçalves

\section{RESUMO}

O presente artigo tem como objetivo principal analisar a estrutura da união poliafetiva, vulgarmente conhecida como poliamor, de sorte a estabelecer, à luz de suas características próprias, um paralelo com outras formas já reconhecidas de entidade familiar pelo ordenamento jurídico brasileiro. O intuito, portanto, será o de constatar, ou não, se referido instituto pode ser detentor de dignidade constitucional diante da clara abertura semântica a respeito do conceito de familia, a teor do rol não taxativo presente na Carta Magna de 1988, mais precisamente no âmbito do artigo 226, da CRF/88. Levou-se em consideração os requisitos/elementos necessários para a caracterização dos entes familiares reconhecidos, bem como os princípios regedores do direito de família, como destaque especial para o primado da dignidade da pessoa humana, princípio da afetividade, da boa-fé objetiva, da proteção da confiança, da fidelidade e da monogamia. A partir de uma abordagem lógico- dedutiva, identificou-se se a poliafetividade está circunscrita única e exclusivamente à simples liberdade de amar (ou ter relacionamentos (sexuais) múltiplos fora da envolvente afetiva, ou se, por outro lado, comporta um enquadramento jurídico à luz do conceito de família e de toda a sua proteção jurídico-valorativa, com maior destaque para o primado da monogamia e da fidelidade. Pautada por uma nova ordem constitucional, a família passou a ser concebida como o grupamento formado por pessoas unidas pelos laços de parentesco e da afetividade e voltadas à busca da felicidade, enquanto desdobramento de sua personalidade. Dito isto, àquela visão de que família deveria ser tida com a reunião de homem e mulher, exclusivamente através do casamento civil, abre-se para o conceito de família decorrente de união estável (art. 226, $\$ 3^{\circ}$, da CF/88), para a família monoparental (art. 226, $\$ 4^{\circ}$, da CF/88)

e agora, mais recentemente, para a família decorrente de união estável homoafetiva, após recente julgamento do Supremo Tribunal Federal nas ADIN de no 4277 e ADPF de no 132. Quanto a esta última, diversos foram os argumentos principiológicos invocados para que referida união homoafetiva pudesse ostentar a validade jurídica própria das entidades familiares até então existentes, entre eles, a dignidade da pessoa humana, a não discriminação em razão da origem ou diversidade sexual, o primado da isonomia entre as entidades familiares, o princípio da nãotaxatividade das entidades familiares ou da pluralidade familiar, da afetividade. Os princípios acima referenciados, em seu conjunto, foram utilizados com o intuito de promover uma aproximação conceitual e material de outras entidades familiares heterossexuais, a exemplo do casamento e da união estável, por restarem presentes todos os elementos caracterizadores das entidades aqui citadas e cujo fundamento base era o afeto entre seus membros. Dentro deste cenário, a especificidade do que aqui se pretende falar conhece seu ponto de partida na ideia de pluralidade familiar à luz da dignidade da pessoa humana e se o ordenamento jurídico poderá abraçar validamente outras configurações familiares.

\footnotetext{
${ }^{1}$ Mestre em Direito pela Universidade de Coimbra, (Portugal) Email: tutortreinamento@gmail.com
} 
Palavras-chave: Poliamor, Dignidade humana, Pluralidade familiar

\begin{abstract}
This article aims to analyze the polyaffection union, commonly known as polyamory, in order to establish, in the light of its own characteristics, a comparison with other forms of family unit already recognized by Brazilian law. Therefore, the objective is to observe whether the practice may or may not hold constitutional dignity in the face of semantic opening of the concept of family, foreseen in the Constitution in a non-exhaustive list, more precisely in accordance with Article 226 of the CRF / 88. It took into account the requirements / elements necessary for defining the family unit already recognized as well as the principles that guide family law, as a special emphasis on the primacy of human dignity, the principle of affection, the objective good faith, protection trust, fidelity and monogamy. From a logical-deductive approach, we identified the polyaffection is only limited exclusively to the simple freedom to love or have multiple sex outside the relationship, or if, on the other hand, is part of a legal framework for the concept of family, supported by all its legal and evaluative protection, with greater emphasis on the rule of monogamy and fidelity. Guided by a new constitutional order, the family came to be conceived as the grouping formed by people united by ties of kinship and affection and focused on the pursuit of happiness, while unfolding of his personality. That said, at that view that family should be seen with the meeting of man and woman, exclusively through civil marriage, opens to the family concept due to common-law marriage (art. 226, paragraph 3, of CF / 88), for the single parent family (art. 226, paragraph 4, of CF / 88) and now more recently for the family due to same-sex union after recent judgment of the Supreme Court of the ADIN No. 4277 and No. 132 of ADPF . As for the latter, many were the arguments and principles invoked so that same-sex union would bear the legal validity that characterized the family entities hitherto existing, between them, human dignity, non-discrimination on grounds of the origin or sexual diversity the primacy of equality between family entities, the principle of non- taxatividade of family entities or family plurality and affection.
\end{abstract}

Keywords: Polyamory, Human dignity, Family plurarity

\title{
I - INTRODUÇÃO
}

O presente artigo tem como objetivo principal analisar a estrutura da união poliafetiva, comumente conhecida como poliamor, de sorte a estabelecer, à luz de suas características próprias, um paralelo com outras formas já reconhecidas de entidade familiar pelo ordenamento jurídico brasileiro. $\mathrm{O}$ intuito, portanto, será o de constatar, ou não, se referida união de indivíduos pode ser detentora de dignidade constitucional diante da clara abertura semântica a respeito do conceito de família, isso a teor do rol não taxativo presente na Carta Magna de 1988, mais precisamente no âmbito do seu artigo 226. 
Levar-se-á em consideração os requisitos/elementos necessários para a caracterização dos entes familiares reconhecidos, explícita ou implicitamente pelo texto constitucional, bem como os princípios regedores do direito de família, com destaque especial ao primado da dignidade da pessoa humana, ao princípio da afetividade, à boa-fé objetiva, à proteção da confiança, à fidelidade e à monogamia.

A par de todo o exposto, tentaremos identificar se a poliafetividade está circunscrita única e exclusivamente à simples liberdade de amar ou ter relacionamentos (sexuais) múltiplos fora da envolvente afetiva, ou se, por outro lado, comporta um enquadramento jurídico à luz do conceito de família e de toda a sua proteção jurídico-valorativa, com maior destaque para o primado da monogamia e da fidelidade.

Nesse sentido, importa referir a importância que a Constituição Federal de 1988 teve perante a dogmática jurídico-civilista, revestida esta que estava da neutralidade das Cartas Constitucionais anteriores e do positivismo jurídico pautado no individualismo e patrimonialismo.

A ideia, defendida por Konrad Hesse acerca da normatividade da constituição, passou a ter mais aplicação no território brasileiro a partir do advento da Lei Fundamental de 1988. Com a Constituição Cidadã não restaram mais dúvidas acerca da robustez normativa da Constituição sobre toda a ordem jurídica infraconstitucional, que subordinada à Norma Maior, encontrou e encontra seu fundamento de validade na dignidade da pessoa humana. O primado constitucional, insculpido no inciso III do art. $1^{\circ}$, passou a ser detentor de uma centralidade jurídica e é com base nele que o tema do poliamor será aqui analisado.

Assim, ao tratar da organização da familia (arts. 226 e 227), a Carta Fundamental avocou para o Estado a regulamentação de institutos anteriormente tratados apenas pelas normas privatísticas, reformulando e adaptando os núcleos familiares à nova realidade social e ao grande objetivo das mesmas que deveria ser o livre desenvolvimento da personalidade de todos os seus membros. Trata-se de mais um exemplo do processo de constitucionalização do direito civil vivenciado nos hodiernos dias.

No âmbito do direito civil de familia, tal ingerência acarretou a releitura de determinados conceitos e institutos jurídicos clássicos (casamento, filiação) e provocou a elaboração de novas entidades jurídicas (familia monoparental, familia homoafetiva), desta feita sob uma nova base principiológica. A mudança dos paradigmas se mostrou suficiente para promover a criação de 
novos direitos (guarda compartilhada, multiparentalidade, reconhecimento da ascendência genética decorrente de reprodução medicamente assistida, alimentos gravídicos) e a uma nova interpretação dos já anteriormente conferidos (poder familiar, direito de visitação dos avós), todos orientados, sobretudo, nos primados da dignidade da pessoa humana, da boa-fé objetiva e da afetividade.

Pautada nessa nova ordem constitucional, a família passou a ser concebida como o grupamento formado por pessoas unidas pelos laços de parentesco e da afetividade e voltadas à busca da felicidade, enquanto desdobramento de sua personalidade.

Dito isto, àquela visão de que familia deveria ser tida com a reunião de homem e mulher, exclusivamente através do casamento civil, abre-se para o conceito de familia decorrente de união estável (art. 226, $\S 3^{\circ}$, da $\mathrm{CF} / 88$ ), para a família monoparental (art. 226, $\S 4^{\circ}$, da $\mathrm{CF} / 88$ ) e agora, mais recentemente, para a família decorrente de união estável homoafetiva, após julgamento do Supremo Tribunal Federal, em sede de controle de constitucionalidade concentrado na ADI de no 4277 e na ADPF de $n^{\circ} 132$.

Quanto a esta última, diversos foram os argumentos principiológicos invocados para que referida união entre pessoas do mesmo sexo pudesse ostentar a validade jurídica própria das entidades familiares até então existentes, entre eles, a dignidade da pessoa humana, a não discriminação em razão da origem ou diversidade sexual, o primado da isonomia entre as entidades familiares, o princípio da não-taxatividade das entidades familiares ou da pluralidade familiar, da afetividade.

Os princípios acima referenciados, em seu conjunto, foram utilizados com o intuito de promover uma aproximação conceitual e material de outras entidades familiares heterossexuais, a exemplo do casamento e da união estável, por restarem presentes todos os elementos caracterizadores das entidades aqui citadas, exceto a envolvente da dualidade sexual, e cujo fundamento base era o afeto entre seus membros.

Dentro deste cenário, a especificidade do que aqui se pretende tratar conhece seu ponto de partida na ideia de pluralidade familiar à luz da dignidade da pessoa humana e se o ordenamento jurídico poderá abraçar validamente outras configurações familiares e que no nosso objeto de estudo convencionou denominar poliamor ou poliafetividade. 


\section{II - O PAPEL DO AFETO E A RECONFIGURAÇÃO DAS ENTIDADES FAMILIARES - A PLURALIDADE SEMÂNTICA DAS FAMÍLIAS E A RECODIFICAÇÃO PAUTADA NO PRINCÍPIO DA AFETIVIDADE E NA DIGNIDADE DA PESSOA HUMANA}

É certo que, no mais das vezes, o ser humano nasce inserido numa estrutura básica social - dita famîlia - na qual iniciará e desenvolverá suas potencialidades enquanto agente realizador de seus próprios anseios e enquanto agente modificador da sociedade na qual está inserida. Talvez por essa sua centralidade a família é reconhecida como célula mater da sociedade, gozando de especial proteção do Estado, nos termos do artigo 226, da Constituição da República Federativa do Brasil.

É igualmente correto afirmar que, estando a familia voltada para a proteção de seus membros, é a responsável pelas inúmeras mudanças de concepção em torno de seu núcleo estrutural, já que desenvolve o papel de traduzir os fatos da vida, os fenômenos sociais e culturais dos sujeitos atores nas mais diversas manifestações humanas.

Dentro desse caldo cultural a família contemporânea - inicialmente tomada como o núcleo formado pela união entre o homem e a mulher que se uniam em torno do matrimônio para a comunhão plena de vida e para a criação e guarda de seus filhos, numa estrutura patrimonializada, hierarquizada e patriarcalizada (familia casamentária) -, começa a ser estruturada sob uma nova perspectiva, desta feita, pautada pelos laços de afetividade em torno de seus membros.

O novo ponto de partida - o afeto - teve o condão de reconhecer a família com base em critérios não estritamente normativos, de sorte a permitir que o núcleo familiar não fosse eminentemente concebido a partir de um viés unicamente institucional, mas tomado a partir da proteção da pessoa humana.

A refuncionalização da família permitiu uma visão descentralizada, igualitária e desmatrimonializada da entidade familiar e com isso, passaram a orbitar conceitos até então não admitidos, como a dissolubilidade do casamento, e a formação de vínculo de parentesco com a adoção, permitindo que as formas de estabelecimento do parentesco não decorresse, apenas e tão somente, do critério cosanguíneo a partir da concepção dos filhos advindos do casamento. 
As mudanças ocorridas com a funcionalização da familia ganharam maior destaque com o reconhecimento de que a entidade, como primeiro núcleo de vivência do ser humano, deve ser meio garantidor de direitos fundamentais $\mathrm{e}$ concretizador dos direitos da personalidade de todos seus membros, sempre sob o influxo da dignidade da pessoa humana e do afeto.

Foi exatamente esta visão igualitária, descentralizada, e democratizada da família que permitiu que o afeto legitimasse outras formas de manifestação de núcleos familiares, com destaque para as familias decorrentes da união estável (artigo 226, $§ 3^{\circ}$, da CF/88) e monoparentais, compostas por um só dos ascendentes e seus descendentes (art. 226, ${4^{\circ}}^{\mathrm{o}}$, da $\mathrm{CF} / 88)$.

O reconhecimento pelo constituinte originário de que o afeto era fonte legitimadora da família e de que a dignidade da pessoa humana seria mola propulsora da mesma, permitiu, na visão de parcela majoritária da doutrina $^{1}$, que toda comunidade que se caracterizasse pela vivência afetiva e que fosse compreendida como estrutura socioafetiva devesse ser concebida com tal, mostrando-se o rol constitucional aqui apresentado (art. 226) como não exaustivo, aberto às mais variadas formas e estruturas familiares.

Assim, na fotografia pós-moderna da família restarão visualizadas a comunidade familiar composta unicamente por irmãos (familia coparental), a familia formada por pessoas sem laços de parentesco, mas que se voltam para um mesmo propósito (família anaparental), famílias decorrentes da recomposição de familias desfeitas (famílias recompostas, reconstituídas, familias-mosaico), todas pautadas pelo afeto e pela busca da felicidade de seus membros, ainda que não haja o reconhecimento expresso pelo constituinte originário e pelo legislador infraconstitucional.

É sob este enfoque, ou seja, o de que as famílias se desenvolvem em torno do afeto e da dignidade da pessoa humana na busca da felicidade de seus membros, que se pretende analisar se verdadeiramente todas as uniões de pessoas, dentro da envolvente afetiva podem ser consideradas entidades familiares e, portanto, detentoras de proteção do ordenamento jurídico.

Nesse contexto, no ano de 2011, o Supremo Tribunal Federal, de forma unânime, mostrou-se favorável acerca da possibilidade de união entre pessoas do mesmo sexo, e assim o fez com eficácia vinculante e erga omnes, nas ações em controle de constitucionalidade concreto, a ADI de $n^{\circ} 4277$ e a ADPF de $n^{\circ} 132$, sob o fundamento de que o ordenamento jurídico brasileiro abraça o primado da dignidade humana como seu fundamento (art. $1^{\circ}$, III, da 
CF/88) dele decorrendo os princípios da isonomia, da proibição de discriminação, do direito à diversidade, concluindo a Corte Suprema que o catálogo constitucional é aberto,

${ }^{1}$ Citam-se, exemplificativamente, como filiados a esta visão, Diogo Leite de Campos, Giselda Maria Fernandes Novaes Hironaka, Luis Edson Fachin, Paulo Luiz Neto Lôbo. 
comportando uma proteção ampla em sede de direitos fundamentais, mormente no que respeita à familia, que teve especial proteção do Estado (art. 226,"caput", da CF/88).

Sob o influxo da decisão acerca da constitucionalidade da união homoafetiva, vieram à tona outras investidas de grupos sociais, também sob a vertente afetiva, no intuito de ser considerados entidades familiares, requerendo o reconhecimento estatal, de sorte a garantir a todos os seus membros os direitos pessoais, patrimoniais e assistenciais daí decorrentes.

Tomando por base à sistemática constitucional de ampla proteção à família, o texto indaga se seria possível o reconhecimento de família que não decorresse diretamente do casamento ou da união estável hetero ou homoafetiva, abarcando também as uniões livres, abertas, que não se caracterizam pela exclusividade de seus membros, a exemplo das uniões poliamorosas, cujos membros se identificam pelo exercício da ampla liberdade sexual, com ou sem afeto.

\section{III - APROXIMAÇÃO CONCEITUAL DA UNIÃO POLIAFETIVA}

O poliamor ou poliafeto pode ser entendido como a união entre mais de duas pessoas, mediante a troca recíproca de afeto, com o objetivo de constituição de familia ou não, sendo esta situação conhecida por todos os sujeitos que participam do relacionamento "aberto", que o aceita mutuamente.

Caracterizaria a união poliafetiva, por exemplo, a convivência notória e pública de dois homens e duas mulheres, um homem e três mulheres, vários homens ou várias mulheres, por exemplo, que se agrupassem pelo afeto e que pudessem estampar ou não o desejo de instituição de família.

Os defensores da união plúrima discorrem que o texto magno, por ter uma aplicação ampla, não traz discriminação acerca de configuração familiar, são sendo isto possível às normas infralegais. Por essa razão, defendem a tese de que as uniões acima destacadas são se submeteriam ao enquadramento tipificado pelo código civil, ou pela lei de registros públicos, pois pertenceriam a uma forma autônoma de entidade familiar.

Noutro norte, mas ainda sustentando a bandeira em favor do poliamor, alguns veem uma aparente semelhança à união estável putativa, comumente intitulada de união estável simultânea ou paralela (DIAS, 2013), haja vista a também pluralidade dos sujeitos que dela participa e da permissão "tácita"de algum de seus membros, que conhece da união paralela e 
não decide romper a conjugalidade de sua união, seja casamentária ou estável, aceitação esta que teria o condão de dar "validade" à segunda união.

O argumento, todavia, parece não ser válido, tendo em vista que a união estável putativa é diversa da entidade que nos propusemos a analisar. A putatividade, ou aparência de união, decorre do desconhecimento de um dos relacionamentos por parte de um dos membros, mas a estrutura do grupo é desenvolvida dentro da socioafetividade. $\mathrm{Na}$ união poliafetiva, esse desconhecimento de outro ou vários membros é inexistente, sendo mesmo a razão de existir dessas uniões a característica da pluralidade.

Poderíamos chegar a ideia de que a união poliafetiva se desenvolveria no afeto, mas a socioafevidade, como marca característica de entidade familiar não necessariamente estaria presente, já que existem relacionamentos dessa natureza que não vislumbram a formação de família, apenas visam a busca de seus integrantes pela sua felicidade a partir do desenvolvimento de sua liberdade sexual.

Se a poliafetividade gira em torno de seus membros e na busca dos mesmos por seus ideais, seria possível então estabelecer o paralelo com uniões estáveis simultâneas ou paralelas, partindo da ideia do conhecimento de todos os seus membros?

\section{III.1 - DIFERENCIAÇÕES NECESSÁRIAS - O POLIAMOR OU POLIAFETO E AS UNIÕES ESTÁVEIS SIMULTÂNEAS: UMA LEITURA A PARTIR DOS PRINCÍPIOS DA AFETIVIDADE E LEALDADE (ENQUANTO VALORES DECORRENTES DA MONOGAMIA)}

A união estável, tomada por seu gênero, foi positivada no âmbito do artigo $226, \S^{\circ}$, da Constituição Federal de 1988, tendo ganhado sua regulamentação infraconstitucional por meio das Leis 8.971/94 e 9.278/96, que concretizaram a possibilidade de uniões pautadas sobretudo pelo afeto, serem detentoras de proteção legal.

Nas supracitadas normas, e agora sob o influxo das decisões emanadas pelo Supremo Tribunal Federal a partir das ADI 4277 e ADPF 132, a união estável nada mais é do que a convivência pública, notória e duradoura entre duas pessoas, do mesmo sexo ou não, voltadas para a constituição da família, vivendo como se casados fossem, sendo estes, pois, seus elementos caracterizadores. Nas ações supramencionadas o princípio norteador das decisões 
foi o respeito à diferença e à proibição de discriminação em razão da etnia, religião ou escolha/opção sexual.

No caso do reconhecimento da união entre pessoas do mesmo sexo, importa referir que o fenômeno da mutação constitucional engendrada no âmbito do artigo 226, §3 $3^{\circ}$,importou na ratificação de que estas uniões estão inseridas no "âmbito normativo" do citado preceito constitucional, verificando-se um autêntico processo informal de construção constitucional (

Assim como a entidade familiar decorrente do casamento, à união estável se emprestam todos os deveres e quase que a totalidade dos direitos decorrentes de seu reconhecimento jurídico, dentre eles, o respeito e a consideração mútuos(artigo 1566, do CC), a lealdade (artigo 1724, do CC) entre os companheiros, o respeito e a assistência mútua. A tais valores, no dizer Pereira, devem ser somados a tolerância, a solicitude e a solidariedade (2004, p. 663).

O dever jurídico decorrente da fidelidade encontra sua base fundante no princípio da proteção da confiança e da boa-fé objetiva, de sorte a permitir o desenvolvimento de seus membros de forma livre, promovendo o crescimento mútuo de todos, possibilitando que a família assim estruturada seja instrumento vetor da dignidade e agente multiplicador dos valores mais intrínsecos que a comunidade social vivencia, legitima, aceita e reproduz.

A função que os valores assumem na compreensão do fenômeno jurídico toma especial destaque, já que o Direito se reporta a um conjunto de estruturas normativas existentes e que se projetam para a realidade social mediante a incorporação de valores que a sociedade deseja ver implantados.

A norma jurídica, assim, é sempre uma expressão da vontade valorativa do legislador que, avaliando positiva ou negativamente um fato social, estipula "a obrigatoriedade, a permissão ou a proibição de determinada conduta" (CARVALHO, 2014, p.21/23). Nessa ordem de ideias, a compreensão do ordenamento passa necessariamente pela consideração dos valores prestigiados e que estejam aptos a concretizar os ideais pretendidos.

Tomada a familia como valor intrínseco à sociedade, nos termos do artigo 226, "caput", da Constituição da República, é que se buscou sua proteção integral enquanto entidade, sobretudo quanto aos seus membros. Com base nesse ideal valorativo é que se consolidou a concepção do pluralismo familiar que se desenvolve a partir dos laços da afetividade, e que deverá gozar de ampla proteção. 
Nesse contexto, concebeu-se a família como valor interpretativo a ser levado em consideração quando das múltiplas disposições normativas no intuito de prestigiar suas mais diversas configurações, mas restando resguardada sua intimidade entitativa.

Assim, é importante referir alguns aspectos que levam a distinguir entre a instituição da família e a entidade familiar (união estável). LEAL destaca que a entidade familiar "se define em princípios de uma eticidade comprometida com a perenização do afeto entre parceiros, ainda que dissolvidos os vínculos do casamento ou da união estável" (2004, p. 601). A família vai muito além da mera conjugalidade, pois nasce e se desenvolve na busca constante de proteção de seus membros e o princípio da solidariedade entre os membros da entidade familiar bem traduz esse dever decorrente do afeto, já que mesmo havendo o rompimento da conjugalidade, serão devidos os alimentos para quem deles necessitam. WELTER chega a falar que a necessidade do dever alimentar repousaria no trinômio necessidade-possibilidadeafetividade (2009, p.56).

Nessa ordem de ideias, seria possível entender que as uniões que se estabelecem de forma paralela, simultânea ou concomitante possam guardar qualquer relação com a entidade familiar estável, seja ela homoafetiva ou não, simplesmente por se acreditar que o afeto esteja presente, não sendo relevante a forma de sua estruturação já que não haveria limites à liberdade de amar?

É que a reciprocidade de afetos entre os diversos membros que as compõe tem premissa fática pautada na boa-fé de pelo menos um de seus membros, que desconhece a união concomitante, numa clara quebra do princípio da proteção da confiança e da boa-fé objetiva por algum de seus membros.

Dando especial destaque ao papel do princípio da proteção da confiança também como elemento caracterizador das relações familiares, ROSSI aduz que o afeto traduz confiança e que a boa-fé é a sua mais próxima tradução, devendo incidir, inclusive, os deveres daí decorrentes. Para o autor, "quando há vedação ao comportamento de forma contraditória à expectativa gerada no outro, é possível dizer-se que estaremos diante de um fato que considerado em sua extensão maior, descumpre preceito essencial à boa convivência e seus efeitos no comportamento da sociedade."(2014, p. 96) 
Exemplo de como a união estável paralela não é recepcionada pelo nosso ordenamento jurídico é retirado da ementa do julgamento a seguir transcrito:

AGRAVO REGIMENTAL NO AGRAVO EM RECURSO
ESPECIAL. DIREITO DE FAMÍLIA.
UNIÕES ESTÁVEIS PARALELAS.
RECONHECIMENTO DE RELACIONAMENTO EXCLUSIVO
DO FALECIDO COM A AUTORA. MATÉRIA FÁTICO-
PROBATÓRIA. SÚMULA 7/STJ. AGRAVO NÃO PROVIDO.
1. Esta Corte Superior entende ser inadmissível o reconhecimento de
uniões estáveis paralelas. Precedentes.
2. Na hipótese dos autos, o Tribunal estadual consignou a existência
de vários relacionamentos concomitantes entre o de cujus e outras
mulheres, inclusive de casamento. Infirmar as conclusões do julgado,
para reconhecer a existência de união estável exclusiva com a autora,
demandaria o revolvimento do suporte fático-probatório dos autos, o
que encontra óbice no enunciado da Súmula 7 desta Corte Superior.
3. Agravo regimental a que se nega provimento ${ }^{2}$.

Nas uniões estáveis putativas, ocorre uma evidente violação dos deveres decorrentes da boa-fé objetiva a partir do momento em que um de seus membros decide vivenciar uma nova união com terceira pessoa, desconhecendo esta a união primeva.

É tida como putativa justamente por ser aparente, por guardar similitude com a união legitimada pelo afeto, pela confiança, pelo respeito e pela convivência marital. Contudo, não poderemos deslembrar que o ordenamento jurídico, em larga escala, não a reconhece como válida, não a reconhece como entidade familiar, apenas empresta alguns efeitos até o dia da decretação de sua nulidade.

Noutro norte, a poliafetividade tem seu marco inicial pautado na constante e recíproca troca afetiva de todos os seus membros (mais de duas pessoas), sem desconhecimento algum por parte de qualquer deles, que a aceita dessa fora, sob esta configuração. Assim, a poliafetividade não entraria em rota de colisão com os deveres decorrentes da afetividade e do dever de confiança, do qual decorre o dever de lealdade.

Sucede, porém, que os relacionamentos poliafetivos, no mais das vezes, não parecem ter como um dos seus fundamentos de validade o afeto, grande identificador e legitimador do núcleo familiar, e sim o desejo claro e incontido de emprestar aos seus membros a legitimidade

${ }^{2}$ AgRg no AREsp 609.856/SP, Rel. Ministro RAUL ARAÚJO, Quarta turma, j. em 28/04/2015, DJe 19/05/2015. 
de uma conduta transgressora, não permitida, que os mesmos não teriam ou ao menos não deveriam ter, fosse essa conduta adotada numa união casamentária ou estável.

Por outro lado, a poliafetividade não seria, como muitos sustentam, uma entidade autônoma e distinta do casamento, como ocorre com a família monoparental, apartada que se encontra das outras entidades por se circunscrever na figura de um dos genitores e seus descendentes, já que comporta a liberdade de convivência múltipla. A união poliafetiva, assim, não estaria cingida a um paralelismo de formas, não devendo repetir o modelo monogâmico de casamento ou de união.

Ora, é esta mesma liberdade de convivência múltipla, diversificada e recíproca que retira toda a sua legitimidade enquanto entidade familiar, posto ser a afetividade valor balizador da fidelidade e do respeito mútuo, ainda que desta constatação não se afirme que estar-se-ia diante da monogamia, inicialmente aplicável ao casamento.

Assim, ao que se vê à luz do ordenamento jurídico é que a monogamia também deva ser um valor afeto às demais relações familiares, seja à união estável ou à união estável homoafetiva, por estas seguirem analogicamente às mesmas disposições previstas para o casamento, ex vi dos artigos 1511 (comunhão plena de vida), 1520 , VI ( não podem casar pessoas casadas), 1565 (condição mútua de consorte/companheiro) e 1565, V (respeito e consideração mútuos), todos do Código Civil de 2002.

Nessa ordem de ideias, importa destacar a proibição de pessoas casadas não poderem contrair nova união, casamentária ou não, sob pena, no primeiro exemplo, de restar caracterizada a bigamia, que encontra, inclusive, sua tipificação no artigo 235, do Código Penal. Apesar da sanção penal não ser aplicável à união estável, pessoas que assim vivem não devem instituir nova união estável, havendo uma verdadeira recusa por parte do ordenamento em reconhecer a segunda união.

Dito isto, se pudéssemos estabelecer um paralelismo de formas com a união estável, rapidamente se chegaria à conclusão de que companheiros também são impedidos de constituir nova união estável - enquanto presentes os requisitos autorizadores do primeiro relacionamento, - em clara conotação ao dever decorrente da fidelidade, da proteção da confiança e da boa-fé objetiva, claras emanações que são do primado da monogamia.

Parcela da doutrina afirma que não se aplicarão às uniões estáveis a proibição decorrente da monogamia, ao menos em sua plenitude (FARIAS, 2013, p.542), suscitando claramente a 
colisão existente entre o primado da monogamia e outros valores como a dignidade da pessoa humana e confiança, aptos que estariam a mitigar/relativizar a monogamia conforme a casuística e conferir status familiar à uniões estáveis aparentes.

Referindo-se expressamente às uniões plúrimas em cotejo com os princípios da dignidade da pessoa humana e o princípio da afetividade, WAQUIM (2012, p.123) pondera que a aceitação que se expressa pela reciprocidade entre todos os membros do relacionamento, pode sim legitimar a constituição de grupo familiar", conferindo o status de entidade. Não seriam simples "parceria ou sociedade de fato, mas entidades familiares propriamente ditas, com todos os direitos advindos da relação"

Mas tal argumento, embora dotado de certo grau de aceitação por parte de alguns, não se presta para as uniões ditas poliafetivas, numa clara afronta aos princípios e valores até aqui invocados, dando-se primazia ao conjunto axiológico-normativo aplicável aos núcleos familiares e não apenas ao afeto, ainda que apontado como forma de desenvolvimento da pessoa humana.

Nas uniões conjugais, o vínculo entre os companheiros deve ser único, a estampar o caráter monogâmico da relação. Essa premissa ainda é a que sedimenta as decisões dos nossos tribunais, como se vê do julgado aqui transcrito:

\section{EMBARGOS INFRINGENTES. AÇÃO DE RECONHECIMENTO DE SOCIEDADE DE FATO. COMPANHEIRO COM RELACIONAMENTOS AMOROSOS PARALELOS. INFIDELIDADE RECONHECIDA. UNIÃO ESTÁVEL NÃO EVIDENCIADA. PREVALÊNCIA DO VOTO MAJORITÁRIO. RECURSO DESPROVIDO.}

Para a configuração da união estável faz-se imprescindível a comprovação dos seguintes requisitos: diversidade de sexo; ausência de matrimônio civil válido e de impedimento matrimonial entre os conviventes; notoriedade da relação; honorabilidade; fidelidade entre os companheiros; e coabitação. "O dever de lealdade 'implica franqueza, consideração, sinceridade, informação e, sem dúvida, fidelidade. Numa relação afetiva entre homem e mulher, necessariamente monogâmica, constitutiva de família, além de um dever jurídico, a fidelidade é requisito natural' (Veloso, Zeno apud Ponzoni, Laura de Toledo. Familias simultâneas: união estável e concubinato. Disponível em http://www.ibdfam.org.br/?artigos\&artigo=461. acesso em abril de 2010).

Uma sociedade que apresenta como elemento estrutural a monogamia não pode atenuar o dever de fidelidade - que integra o 
conceito de lealdade - para o fim de inserir no âmbito do Direito de Familia relações afetivas paralelas e, por consequência, desleais, sem descurar que o núcleo familiar contemporâneo tem como escopo a busca da realização de seus integrantes, vale dizer, a busca da felicidade.

As uniões afetivas plúrimas, múltiplas, simultâneas e paralelas têm ornado o cenário fático dos processos de família, com os mais inusitados arranjos, entre eles, aqueles em que um sujeito direciona seu afeto para um, dois, ou mais outros sujeitos, formando núcleos distintos e concomitantes, muitas vezes colidentes em seus interesses.

Ao analisar as lides que apresentam paralelismo afetivo, deve o juiz, atento às peculiaridades multifacetadas apresentadas em cada caso, decidir com base na dignidade da pessoa humana, na solidariedade, na afetividade, na busca da felicidade, na liberdade, na igualdade, bem assim, com redobrada atenção ao primado da monogamia, com os pés fincados no princípio da eticidade ${ }^{3 "}$.

Pelo visto, a tão propalada liberdade de amar, ou para amar, encontraria barreiras ou o limite dos limites, nos próprios elementos caracterizadores das entidades familiares, ou seja, só poder-se-ia admitir como entidade familiar àquelas formadas por pessoas humanas e baseadas no afeto, na ética e na solidariedade recíproca.

\section{2 - DOS RELACIONAMENTOS POLIAFETIVOS E SEU ENQUADRAMENTO LEGAL À LUZ DO ORDENAMENTO JURÍDICO}

A estabilidade do grupamento humano que se firma no propósito de autodeterminação de seus membros através da transmissão da cultura e formação da pessoa humana é tida legitimamente como família, daí decorrendo todos efeitos pessoais, patrimoniais e assistenciais.

A poliafetividade não nos parece uma cultura disseminada em nossa sociedade, resulta apenas de um grupo de pessoas (ainda que crescente) que querem ter liberdade de amar sem que The seja atribuída qualquer conduta desonrosa, espúria ou desabonadora, conduta esta que acarretaria a possibilidade da quebra da conjugalidade e mais adiante, da própria entidade familiar.

\footnotetext{
${ }^{3}$ STJ, REsp n. 1.157.273/RN, Rel. Ministra Nancy Andrighi, Terceira Turma, j. em 15-5-2010.
} 
Todavia, as uniões poliafetivas, enquanto grupamento de pessoas em torno de uma finalidade comum (consistente em ter relacionamentos sexuais múltiplos com desejo de instituir família ou não), podem e devem caracterizar sociedade em comum, lhes sendo conferidos direitos no campo obrigacional, evitando-se, assim, o enriquecimento ilícito por qualquer de seus membros, sobretudo nas relações patrimoniais em que se verifique a aquisição de bens e os direitos e deveres deles decorrentes.

Nessa seara, seria sim possível seu reconhecimento jurídico, inclusive mediante registro público, mas tal registro não terá o condão de legitimar a unidade social como entidade familiar, já que não encontra os contornos balizadores da mesma, ainda que tenha, eventualmente, a afetividade entre seus membros.

A afetividade, pois, não será elemento único, tão menos absoluto, apto à caracterizar a familia enquanto entidade, porque esta resultará da conjugação dos princípios constitucionais e dos valores consagradores da ente no seio social.

Pensar na ordem inversa, permitiria aos membros da referida união poliafetiva gozar de todos os direitos pessoais (uso do nome, filiação, alimentos), patrimoniais (meação, herança) e assistenciais.

\section{IV - ALGUNS DOS TÓPICOS PROBLEMÁTICOS RELACIONADOS AO POLIAMOR}

Partindo-se das primeiras luzes que já foram lançadas sobre o tema, o texto se arrisca numa visitação de algumas esquinas problemáticas. O presente estudo lista, de forma não exauriente, um pequeno rol de problemas jurídicos decorrentes da eventual aceitação do poliamor como unidade familiar.

Mais do que conceder respostas prontas e acabadas acerca dos hard cases derivados da alegada liberdade de amar, o item agora principiado vai se limitar a pontuar a intriga, deixando para o legislador e para a sociedade o amadurecimento acerca das respostas mais consentâneas com o ordenamento jurídico brasileiro.

A normativa vigente (art. 1.597 do Código Civil Brasileiro) estabelece, respeitadas algumas balizas temporais, que as crianças geradas na constância do casamento são presumidamente filhas biológicas do cônjuge varão. E na hipótese de a mulher estabelecer uma união poliafetiva com 3 ou 4 homens, como restará enfrentado o problema? A criança gerada no decorrer deste relacionamento plural será presumidamente de algum dos homens? 
Já no que tange ao estabelecimento da filiação, a criança ostentaria a filiação biológica ou a filiação plural socioafetiva (multiparentalidade socioafetiva)?

Outro problema decorrente da hipotética união afetiva plúrima é se saber quem e em que medida poderia exercer o poder familiar. E na hipótese de conflitos de concepções no exercício do referido poder familiar, quais seriam os caminhos a percorrer para se enfrentar as eventuais colisões ideológicas?

Apenas a título de densificação, veja-se um caso concreto: os pais ainda detém o direito de indicar aos seus filhos menores a educação religiosa que lhes convier. E na hipótese de uma mulher católica se relacionar com 3 ou 4 homens de diferentes crenças religiosas, como ficará a orientação metafísica das crianças?

Outro tema que precisa ser enfrentado pelo legislador é o que diz correlação com a guarda das crianças na eventualidade do término da relação poliafetiva. A guarda será compartilhada? Compartilhada por todos e em igual proporção? Se a vivência cotidiana tem mostrado que a guarda compartilhada entre um pai e uma mãe traz alguns efeitos negativos para a criança, o que imaginar de uma guarda compartilhada entre múltiplos lares.

Outro aspecto que não pode ser olvidado pelo legislador é o que diz correlação com os direitos hereditários. A criança concebida no contexto de uma relação com pluralidade de parceiros teria o direito de herdar de todos eles? Iria integrar diversos núcleos familiares? O eventual direito de aceder a diversas famílias e heranças atentaria ou não contra o primado constitucional da igualdade?

No que pertine ao direito eleitoral e no quadro das inelegibilidades, o filho gerado na constância das relações plurais seria inelegível com relação a todos os partícipes do relacionamento? Os próprios membros da comunidade afetiva estariam alcançados pela inelegibilidade reflexa? A imposição de uma incidência mais alargada da inelegibilidade por parentesco é ou não respeitosa para com a ideia de isonomia?

Os breves e iniciais apontamentos acima hão de servir para uma reflexão mais profunda dos direitos e dos deveres decorrentes da eventual aceitação do poliafeto como unidade familiar, tudo visando que se ultrapasse uma abordagem superficial, simplória e simplista e que ignora toda uma complexa gama de consequências e desdobramentos jurídicos. 


\section{V - CONCLUSÕES}

Tomada a família como valor intrínseco à sociedade, nos termos do artigo 226, "caput", da Constituição da República, é que se buscou sua proteção integral enquanto entidade, sobretudo quanto aos seus membros. Com base nesse ideal valorativo é que se consolidou a concepção do pluralismo familiar que se desenvolve a partir dos laços da afetividade, e que deverá gozar de ampla proteção.

Sob a ótica constitucional inclusiva, tentamos estabelecer um paralelo entre as uniões estáveis putativas, as uniões estáveis simultâneas e as uniões poliafetivas, a partir da ideia da pluralidade familiar e do escopo maior da família que é a busca da felicidade de seus membros, à luz do primado da dignidade humana.

De sorte a perseguir uma possível autonomização das uniões poliafetivas, analisamos as estruturas e elementos característicos de cada união a partir do sistema de princípios consagradores da familia, do qual percebemos que o afeto permeia todos eles, muito embora a estrutura da socioafetivadade não esteja representada em todas, haja vista a falta a perenização do afeto em relações que se estabelecem de forma paralela ou simultânea, tenham ou não os seus atores sociais conhecimento da convivência paralela.

Assim, constatamos que dentro das estruturas das uniões familiares, coexistem uma série de princípios e comandos normativos concretizadores do núcleo social, aptos a normatizar uma diversidade de condutas dos indivíduos que se propõe em viver perante a sociedade gozando das prerrogativas só a ela inerentes, como o instituto do bem de família.

Nesse contexto e a par das estruturas analisadas, o afeto seria a expressão mais fiel da confiança e esta, da boa-fé objetiva, a qual estatui o dever de conduta proba e ética por parte dos membros familiares e que estipula ser abusiva de direito a conduta que viola o exercício regular de um direito reconhecido, que é a instituição da entidade familiar.

Afeto (confiança) e boa-fé objetiva (conduta proba) são traduzidas para o contexto das relações pessoais de família em total sintonia com o primado da monogamia, valor jurídico inicialmente decorrente do casamento, mas afeto às demais relações familiares, seja à união estável ou à união estável homoafetiva, por estas seguirem analogicamente às mesmas disposições previstas para o casamento, ex vi dos artigos 1511 (comunhão plena de vida), 1520, VI (não podem casar pessoas casadas), 1565 (condição mútua de consorte/companheiro) e 1565, V (respeito e consideração mútuos), todos do Código Civil de 2002. 
Concluímos, portanto, que as uniões poliafetivas não poderiam gozar da mesma proteção jurídica de que desfrutam as demais unidades familiares, eis que não guardam similitude com as entidades já reconhecidas pelo ordenamento. $\mathrm{O}$ argumento, mobilizado por alguns, de que se deve proteger as minorias e que as relações afetivas plurais estariam dentro deste contexto minoritário, não se mostra sólido para dar ao agrupamento humano em questão a equiparação às famílias atualmente aceitas.

\section{REFERÊNCIAS BIBLIOGRÁFICAS}

CALDERÓn, Ricardo Lucas. Princípio da afetividade no direito de família. Rio de Janeiro: Renovar, 2013.

CARVALHO, Paulo de Barros. "A família como valor". In MARTINS. Ives Gandra da Silva; CARVALHO, Paulo de Barros (Coordenadores). O Direito e a família. São Paulo: Noeses, 2014. pp. 19/33 (especial interesse às pp. 21/23).

DIAS, Maria Berenice. Manual de direito das famílias. São Paulo: Editora Revista dos Tribunais, 2013.

FARIAS, Cristiano Chaves de; ROSELVALD, Nelson. Curso de direito civil. Salvador: Jus Podivm, 2013.

LEAL, Rosemiro Pereira. Processo e eticidade familiar constitucionalizada. In PEREIRA, Rodrigo da Cunha (Coordenador). Afeto, ética, família e o novo código civil. Belo Horizonte: Del Rey, 2004, pp. 593-606.

PEREIRA, Rodrigo da Cunha. Princípios Fundamentais Norteadores do Direito de família. São Paulo: Saraiva, 2012.

PEREIRA, Tânia da Silva. "Famílias possíveis: novos paradigmas na convivência familiar". In CUNHA, Rodrigo Pereira da (Coordenador). Afeto, ética , família e novo código civil. Belo Horizonte: Del Rey, 2004. pp. 653. 
ROSSI, Luiz Fernando Salles. O abuso de direito nas relações de família. In SILVA, Regina

Beatriz Tavares da; NETO, Theodureto de Almeida Camargo (Coordenadores). Grandes temas de direito de família e das sucessões. São Paulo: Saraiva: 2014, pp. 87-111.

WAQUIM, Bruna Barbieri. Relações simultâneas conjugais: o lugar da outra no direito de família. Maranhão: Café e Lápis, 2011.

WELTER, Belmiro Pedro. Teoria Tridimensional do direito de família. Porto Alegre: Editora Livraria do Advogado, 2009. 